\title{
A SMART GPS-BASED IoT SYSTEM FOR BLACKSPOT NOTIFICATION
}

\author{
Billy Owire ${ }^{1}$, Bernard Shibwabo Kasamani ${ }^{1 *}$ \\ ${ }^{1}$ Strathmore University, Nairobi, Kenya - bshibwabo@strathmore.edu
}

KEY WORDS: IoT, black spot, blackspot, driver, audio, notification, Arduino, GPS, GSM, microcontroller, TX, RX.

\begin{abstract}
:
An accident blackspot is a length of the road marked as having high road accidents potential. Various highways have become a nightmare to passengers, drivers and pedestrians in the recent past. One of the common causes of road accidents is a driver being unfamiliar with a road. Despite authorities using various methods to raise awareness of blackspots including the use speed guns detectors the rate of the accidents on the roads is still in an alarming rate. More often, signposts on the road can be vandalized or even be hit by a reckless driver. There is also an assumption that every driver reads and understands signposts. We propose an IoT system embedded on a vehicle and having ability to sense a blackspot from a given distance. After sensing the blackspot, the system then provides an audio directive that notifies a driver to be more careful and avoid overtaking. The proposed system was developed using GPS, microcontrollers, and GSM mobile technology. The system was tested using coordinates extracted from road sections marked as blackspots. The proposed system sends notifications to end users using GSM system chip.
\end{abstract}

\section{INTRODUCTION}

A road accident is an undesired event on the road involving a car or several cars whose outcome is undesired (Jørgensen, 2009; Manyara, 2016). The outcome can be as fatal as loss of lives, severe injuries and damage to the properties like cars, houses and roads. The road accidents affect economic growth of a country and leaves families of the deceased struggling. According to Ekpenyong (2015), causes of road accidents are categorized into human errors, mechanical problems and environmental factors. Amongst these human errors takes the lion share of about $90 \%$. The human errors entail reckless driving, being unfamiliar with the road, driving while drunk, ignoring road signs and, inadequate driving skills. Travel demand can also lead to road accidents, when many people own vehicles there shall be many people driving on the road and this affect positively the chances of an accident being reported.

According to WHO (2009), the effects of road accidents include destabilizing families' financial sates plunging families to poverty. Families lose their loved as result of these road accidents. The situation has also forced many families to spend their only savings to treat causalities of the road accidents. There is need to address this situation using technological ways. The key players in road transport have in the recent past shifted the blame of road accidents occurrence to poor state road network. However, some world developing economies have spent quiet a good share of their budgets constructing good roads. However, this effort has born little fruits because the number of accidents continues to increase (Olemo, 2016). Therefore, the stakeholders need to embrace alternative measures to lower the rate of road accidents.

According to Malik (2016), most accidents have been attributed to the following main causes, effects and location of occurrence. - Occurring in straight stretches due to over speeding.

- Occurring in sharp bends due to inadequate site distance, lack or poor traffic guidance, poor road marking and poor road geometry designs.

- Head-on collisions due to over speeding and bad overtaking practices. - Pedestrian's inadequate understanding of road signs and lack
of road markings.

To reduce the effects, right decisions need to be factored into transport systems. Pedestrians and drivers need to be provided with adequate traffic guidance; road signs implementation techniques need to have a new face. The road blackspot identification study is fundamental in the aim of reducing number road accidents. Even though the definition of blackspots tends differ from country to country, the deviation in the meaning leans towards the physical nurture of this section of the road. The characteristic of this section of the road remains similar among how different countries define it, that is the section of the road that high chances of accidents occurring (Chen, 2012).

The study focuses on building a system to notify drivers using an audio signal whenever they are approaching blackspot on the road. There exists technology to send notifications to the moving cars. This can be achieved by having a sensor on the moving vehicle, this sensor shall read the coordinates and decode whether the coordinate range is marked as a blackspot upon which it will trigger a notification to the driver.

\section{LITERATURE REVIEW}

Even though there are policies to ensure dangerous sections are made aware to road users, this is not accomplished to the latter. Some road signs are too small or too huge and some are confusing (Lewis, 2018; Min \& Wynter, 2011). This has given pedestrians and motorists a difficult time in way finding. When a road sign indicating a black spot takes time to comprehend or even read it leads to poor decisions and may consequently result to a road accident. GPS has improved navigation by the drivers. However, drivers might not find time to read, interpret the GPS maps. Some motorists even fail to update the GPS data of their vehicles. Drivers can also fail to spot the signs especially when over speeding. Anbaroglu et al. (2016) as well as Younshik (2017) highlight the relationship between travel demand and non-recurrent traffic congestion. Non-recurrent traffic congestion is associated with over speeding. Alternative 
approaches can be used to counter the limitations of using road signage to alert road users of black spots.

Traffic signs are thus effective when they are clearly seen. When the weather is foggy, it can also be difficult to fully comprehend the message conveyed by a given road sign. Some studies (Dumbaugh, Saha \& Merlin, 2020; Tan, Petterson \& Petersson, 2007) highlight the use of retro-reflective material to enhance the visibility of traffic signs at night. The effectiveness of retro-reflective traffic signs has proven to be ideal at night. The approach also requires constant monitoring as vehicle can hit this post. The IoT GPS based approach of identifying black spots while driving will eliminate the need of these traffic signs.

Road traffic signs include black spot signs; damage to these signs is amongst the big challenges that road users' encounter. The damages are categorized into six groups that is bending/cutting, cracking, vandalism, peeling and fading. Bending can be as result of strong winds or when hit by a vehicle. Vandalism can result from deliberate action by human beings (Khalilikhah \& Heaslip, 2016). The damage to traffic signs brings about safety concerns to drivers and other road users. Therefore, other measures such using GPS based IoT systems need to replace the conventional methods.

\section{METHODOLOGY}

Rapid Application Development approach was adopted for this study. There are three wide phases to Rapid Application Development (RAD) that engage both users and analysis in assessment, design, and implementation. This study took an experimental approach that involves gathering of arbitrary coordinates, which denote and represent blackspots. The study is then validated by creating an IoT GPS based system for testing coordinates identified to represent blackspots. The built IoT system is a proof of concept under study and tends to be as objective as possible by using coordinates from different locations.

A highway in Kenya was selected to be location for testing this study mainly because of the notorious blackspots on the Nakuru-Eldoret highway. The GPS co-ordinates of Salgaa's blackspot which is along this highway is $\left(0.2048^{\circ} \mathrm{S}, 35.8479^{\circ}\right.$ E). Salgaa is a leading blackspot in Kenya, if the quantity of road accidents that have occurred along this point is anything to go by. Figure 1 shows the Salgaa area with the main road cutting between the top left and bottom right of the image.

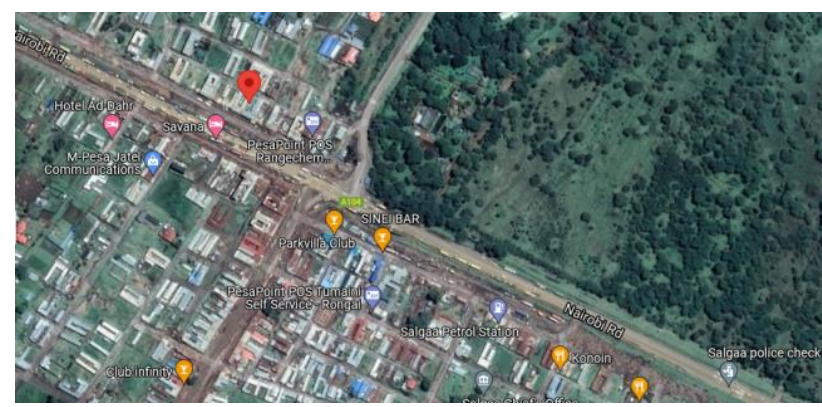

Figure 1. Google Maps Capture of Salgaa.

Drivers along the highway were chosen as respondents for interview questions under this study. The questions aimed at getting requirements about the systems user requirements. This ensured that the proposed system has the users' expectations incorporated. Sampling was done in random manner selecting personal car, public and institutional car drivers.

The system requirements from the drivers were analyzed to form a basis in which the GPS blackspot identification system was to be constructed. The drivers' requirements helped in component identification and prototype design.

The requirements were transformed to appropriate design models. Each requirement identified was modeled into a design construct that depicts individual components of an IoT GPS based blackspot identification system. The design is fundamental because it gives high level view of the final product is expected to look like. The design focused on how individual projects components shall be interfacing with each other, that is how Arduino micro-controller was to be connected to GPS device, and how the GSM module was to be linked to GPS and relay alerts appropriately to the actual mobile device. Unified language modeling (UML) diagrams approach was to give a clear picture of the desired designs.

The designed prototype was later transformed to the testable IoT system. The coding part of the system was done using Arduino studio; a sketch program was developed using C program language construct. The algorithm developed in this phase was purposed to be able to accept several points inform of GPS coordinates, send signal to a preferred mobile device alerting a driver whenever he comes to regions coordinates indicated as blackspots.

Finally, all the project components; Arduino, GSM and GPS were integrated to form a complete IoT system subsequent to testing of every unit. Testing was done using a moving car, with the IoT system installed. The testing was done in iterative manner to have all sampled coordinates to ascertain the reliability and robustness of the system. To ensure reliability, the tests were done using coordinates from different locations which represent the blackspots.

\section{THE SMART GPS-BASED IOT SYSTEM}

\subsection{System Architectural Design}

The system architecture was modelled based on the following requirements that were obtained from drivers as well as Mutune et al. (2017) and Kenya Police Service (n.d):

- The system should be able to locate the blackspot at a distance via Global Positioning System (GPS). Once that has been done, an SMS should be sent to the driver approaching a blackspot and an audio notification generated.

- The system should notify a driver when they are approaching a blackspot.

- The system should caution a driver when they get to the blackspot.

- The system should advice the driver on how to drive safely through the blackspot to avoid accidents.

- The system should inform a driver when he/she has driven out of the danger zone and tell them that they drove through the blackspot safely.

- The driver should be notified that they are approaching a blackspot when they are 150 meters from the blackspot.

- An SMS audio is to be sent to the driver of the vehicle approaching the blackspot through the phone number of their registered SIM card. 
When the GSM is triggered, it sends an audio SMS to the driver alerting them that they are approaching a blackspot and gives them some guidelines on safe driving through the blackspot. This should help improve driver awareness. The architecture of the proposed system is illustrated in Figure 2.

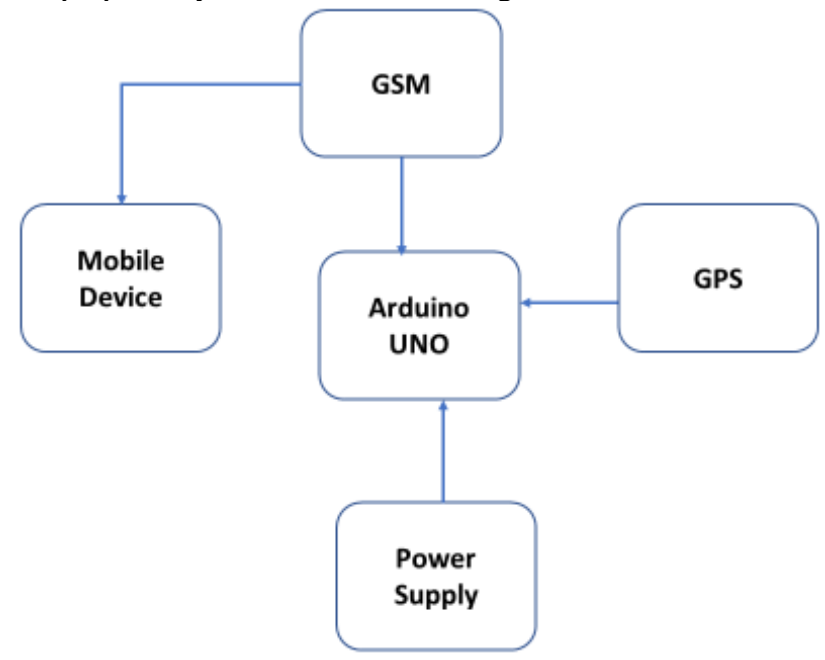

Figure 2. System Architecture.

The blackspot audio notification process begins when a driver is approaching a blackspot and is within a radius of 150 meters of it. This is with the aid of the Global Positioning System (GPS). The Global System for Mobile Communication (GSM) is then triggered. When the GSM is triggered, it sends an audio SMS to the driver alerting them that they are approaching a blackspot and gives them some guidelines on safe driving through the blackspot. This helps reduce blackspot related accidents. When the driver drives out of the blackspot, the system informs them that they are safe now. This helps drivers make appropriate decisions about the section of the road they are driving at.

\subsection{Experimental Setup}

The experiments were conducted on an Intel Centrino 1.6 GHZ Processor with the following required components: Arduino Uno, GSM Module, GPS Module, 16x2 LCD, Power Supply, Connecting Wires. The GPS module sends plenty of data related to tracking position in real-time. This is done in NMEA format (see Figure 3). NMEA format consists of several sentences, in which we only need one sentence. This sentence starts from \$GPGGA and contains the coordinates, time and other useful information. GPGGA stands for Global Positioning System Fix Data.

Coordinates can be extracted from \$GPGGA string by counting the commas in the string. Suppose you find \$GPGGA string and stores it in an array, then Latitude can be found after two commas and Longitude can be found after four commas. Now these latitude and longitude can be put in other arrays.

\$GPGGA,104534.000,7791.0381,N,06727.4434,E,1,08,0.9,510 .4, M,43.9, M, *47

\$GPGGA, HHMMSS. SSS, latitude, N, longitude, E,FQ,NOS, HDP, altitude, M, height, M, checksum data.

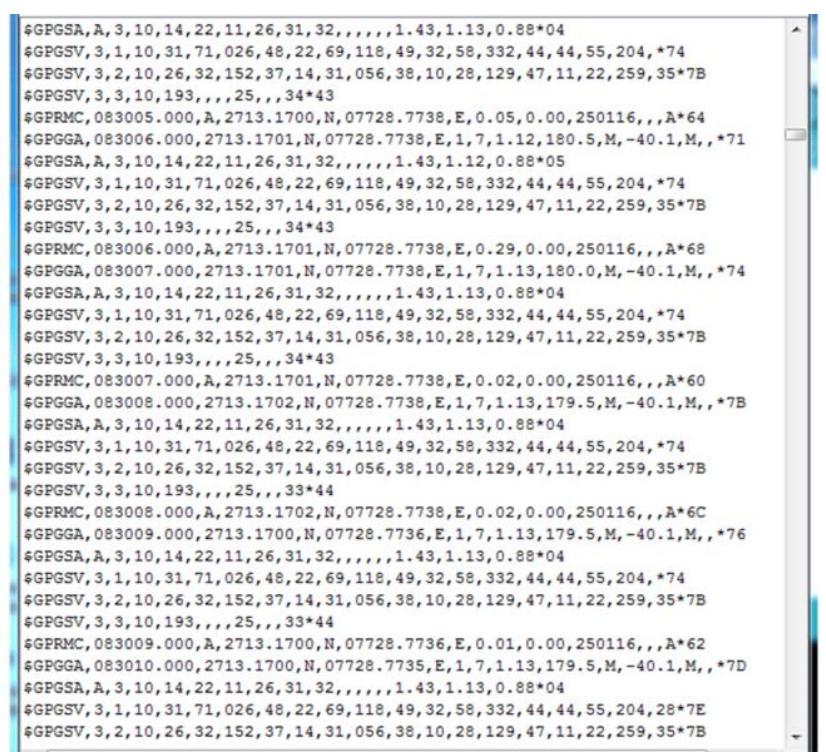

Figure 3. Coordinate Raw Data.

GSM module's Tx and Rx pins of are directly connected to pin $\mathrm{Rx}$ and Tx of Arduino. GSM module is also powered by $12 \mathrm{v}$ supply. Sent message is received by GSM module which is connected to the system and sends message data to Arduino. Arduino reads it and extract main message from the whole message, compare it with predefined message in Arduino. If any match occurs, then Arduino reads coordinates by extracting \$GPGGA String from GPS module data (GPS working explained above) and send it to user by using GSM module. This message contains the coordinates of vehicle location. Figure 4 presents the \$GPGGA String, along with its description:

\begin{tabular}{l|l|}
\hline Identifier & Description \\
\hline \$GPGGA & Global Positioning System Fixed Data \\
\hline HHMMSS.SSS & Time in hour, minute, seconds, and milliseconds format \\
\hline Latitude & Latitude(Coordinate) \\
\hline N & Direction N=North, S=South \\
\hline Longitude & Longitude(Coordinate) \\
\hline E & Direction E=East, W=West \\
\hline FQ & Fixed Quality Data \\
\hline NOS & Number of Satellites being used \\
\hline HPD & Horizontal Dilution of Precision \\
\hline Altitude & Altitude from sea level \\
\hline M & Meter \\
\hline Height & Height \\
\hline Checksum & Checksum Data \\
\hline
\end{tabular}

Figure 4. \$GPGGA Coordinate Data String.

In programming, we first include libraries and define pins for software serial communication and a variable with an array for storing data. Software Serial Library is used to allow serial communication on pin 10 and 11 .

\#include <SoftwareSerial.h>

SoftwareSerial gps(10,11); // RX, TX

char str[70];

String gpsString="'";

.......

........

Here array $\operatorname{str}[70]$ is used for storing received message from GSM module and gpsString is used for storing GPS string. char 
*test=" $\$ G P G G A$ " is used to compare the right string that we need for coordinates. Next, was an initialization of serial communication, GSM \& GPS module in setup function which showed the messages on LCD.

Initialization function 'gsm_init()' is used for initializing and configuring the GSM Module, where firstly, GSM module is checked whether it is connected or not by sending 'AT' command to GSM module. If response OK is received, means it is ready. System keeps checking for the module until it becomes ready or until ' $\mathrm{OK}$ ' is received. Then ECHO is turned off by sending the ATE0 command, otherwise GSM module will echo all the commands. Then finally Network availability is checked through the 'AT+CPIN?' command, if inserted card is SIM card and PIN is present, it gives the response +CPIN: READY. This is also check repeatedly until the network is found.

\subsection{System Testing}

The testing process consisted of test cases against real blackspots. The program was uploaded to the microcontroller, which is integrated with the GPS and GSM components. On receiving a signal from the microcontroller, the GSM module conveyed appropriate message to the mobile device.

A moving vehicle along the road with black spots while carrying the device was used to simulate a real-life case. After this, notifications were monitored from each of designated zone. The first expected notification was expected to be sent when the vehicle approached the black spot, second was to be sent while the vehicle was in the black spot region and the third was to be sent when the vehicle has moved past the region.

The expected result was either a success or a failure to detect the black spot and sent a notification. The success message for coordinates just before the black spots represents a message that goes to the user's mobile which is later converted to audio message. This message is "note that you are approaching a black spot section of this road". While driving, the user can set the message to be delivered in audio (voice) format to avoid a situation where the driver will be distracted while reading the text.

On reaching the blackspot region another message is sent to the driver's mobile phone which says, "you are now at the black spot section, kindly adjust your speed accordingly and avoid overtaking". After cruising past the black spot region, the final message is sent "you have driven safely on the black region, you now out of the black spot region".

The five blackspots that were used in the tests are $[8,9]$ : Salgaa Blackspot - Nakuru County, Mombasa Road between Bellevue to Cabanas - Nairobi County, Tsavo - Maungu - Voi Road Section - Coast Region, Kinungi - Naivasha - Gilgil Toll Station - Nakuru County, and Kiganjo - Naromoru Road Nyeri County. Test results for two of these five blackspots are as follows:

\section{Test 1: Salgaa Blackspot - Nakuru County}

Co-ordinates: Latitude: -0.204653

Longitude: 35.846642

$\left(0^{\circ} 12\right.$ ' 16.7508” S, $35^{\circ} 50$ ' 47.9112” E)
Table 1 shows an explanation of the tests that were conducted at the notorious Salgaa Blackspot. The table also explains the expected action of the system from when a user is approaching a blackspot, to when the user gets to the blackspot, until the point when the user exits the blackspot. The system is supposed to notify the user of the system by sending them an audio SMS informing them of their proximity to the blackspot and to give them guidelines on how to safely drive through a blackspot.

\begin{tabular}{|c|c|c|c|}
\hline $\begin{array}{l}\text { Blackspot } \\
\text { Location }\end{array}$ & User Action & $\begin{array}{l}\text { Expected } \\
\text { System } \\
\text { Action }\end{array}$ & $\begin{array}{l}\text { Actual } \\
\text { System } \\
\text { Action }\end{array}$ \\
\hline $\begin{array}{l}\text { Salgaa } \\
\text { Black } \\
\text { Spot }\end{array}$ & $\begin{array}{l}\text { Approaches } \\
\text { Blackspot (Is } \\
\text { within a } \\
\text { radius of } \\
150 \mathrm{~m})\end{array}$ & $\begin{array}{l}\text { The system } \\
\text { should notify } \\
\text { the user by } \\
\text { sending an } \\
\text { audio SMS } \\
\text { that they are } \\
\text { approaching } \\
\text { a Blackspot. } \\
\text { The system } \\
\text { should give } \\
\text { the user } \\
\text { some guidelines on } \\
\text { how to safely } \\
\text { drive through } \\
\text { a blackspot. }\end{array}$ & $\begin{array}{l}\text { The user was } \\
\text { notified on } \\
\text { approaching } \\
\text { the } \\
\text { blackspot. } \\
\text { The user } \\
\text { received } \\
\text { guidelines on } \\
\text { how to safely } \\
\text { drive through } \\
\text { the } \\
\text { blackspot. }\end{array}$ \\
\hline $\begin{array}{l}\text { Salgaa } \\
\text { Blackspot }\end{array}$ & $\begin{array}{l}\text { Gets to the } \\
\text { Blackspot (Is } \\
\text { within the } \\
\text { blackspot } \\
\text { coordinates) }\end{array}$ & $\begin{array}{l}\text { The system } \\
\text { should notify } \\
\text { the user that } \\
\text { they have } \\
\text { entered the } \\
\text { region of the } \\
\text { blackspot. }\end{array}$ & $\begin{array}{l}\text { The user is } \\
\text { notified that } \\
\text { they have } \\
\text { entered the } \\
\text { blackspot } \\
\text { region. }\end{array}$ \\
\hline $\begin{array}{l}\text { Salgaa } \\
\text { Blackspot }\end{array}$ & $\begin{array}{l}\text { Exits the } \\
\text { Blackspot (Is } \\
\text { not within } \\
150 \mathrm{~m} \text { of the } \\
\text { Blackspot) }\end{array}$ & $\begin{array}{l}\text { The system } \\
\text { should notify } \\
\text { the user that } \\
\text { they have } \\
\text { exited the } \\
\text { region of the } \\
\text { blackspot. }\end{array}$ & $\begin{array}{l}\text { The user is } \\
\text { notified that } \\
\text { they have } \\
\text { exited the } \\
\text { blackspot } \\
\text { region and } \\
\text { that they are } \\
\text { safe. }\end{array}$ \\
\hline
\end{tabular}

Table 1. Test Case One.

Test 2: Mombasa Road between Bellevue to Cabanas Nairobi County

\author{
Co-ordinates: Latitude: -1.3170846489693244 \\ Longitude: 36.833724975585945 \\ $\left(1^{\circ} 19^{\prime} 1.506 ” \mathrm{~S}, 36^{\circ} 50\right.$ ' $\left.1.41 ” \mathrm{E}\right)$
}

Table 2 is an explanation of the tests that were conducted at the Mombasa Road between Bellevue to Cabanas Blackspot. The table also explains the expected action of the system from when a user is approaching a blackspot, to when the user gets to the blackspot, until the point when the user exits the blackspot. The system is supposed to notify the user of the system by sending them an audio SMS informing them of their proximity to the 
blackspot and to give them guidelines on how to safely drive through a blackspot.

\begin{tabular}{|c|c|c|c|}
\hline $\begin{array}{l}\text { Blackspot } \\
\text { Location }\end{array}$ & User Action & $\begin{array}{c}\text { Expected } \\
\text { System } \\
\text { Action }\end{array}$ & $\begin{array}{l}\text { Actual } \\
\text { System } \\
\text { Action }\end{array}$ \\
\hline $\begin{array}{l}\text { Mombasa } \\
\text { Road } \\
\text { Between } \\
\text { Bellevue } \\
\text { to } \\
\text { Cabanas } \\
\text { Blackspot }\end{array}$ & $\begin{array}{l}\text { Approaches } \\
\text { Blackspot (Is } \\
\text { within a } \\
\text { radius of } \\
150 \mathrm{~m} \text { ) }\end{array}$ & $\begin{array}{l}\text { The system } \\
\text { should notify } \\
\text { the user by } \\
\text { sending an } \\
\text { audio SMS } \\
\text { that they are } \\
\text { approaching } \\
\text { a Blackspot. } \\
\text { The system } \\
\text { should give } \\
\text { the user } \\
\text { some guidelines on } \\
\text { how to safely } \\
\text { drive through } \\
\text { a blackspot. }\end{array}$ & $\begin{array}{l}\text { The user was } \\
\text { notified on } \\
\text { approaching } \\
\text { the } \\
\text { blackspot. } \\
\text { The user } \\
\text { received } \\
\text { guidelines on } \\
\text { how to safely } \\
\text { drive through } \\
\text { the } \\
\text { blackspot. }\end{array}$ \\
\hline $\begin{array}{l}\text { Mombasa } \\
\text { Road } \\
\text { Between } \\
\text { Bellevue } \\
\text { to } \\
\text { Cabanas } \\
\text { Blackspot }\end{array}$ & $\begin{array}{l}\text { Gets to the } \\
\text { Blackspot (Is } \\
\text { within the } \\
\text { blackspot } \\
\text { coordinates) }\end{array}$ & $\begin{array}{l}\text { The system } \\
\text { should notify } \\
\text { the user that } \\
\text { they have } \\
\text { entered the } \\
\text { region of the } \\
\text { blackspot. }\end{array}$ & $\begin{array}{l}\text { The user is } \\
\text { notified that } \\
\text { they have } \\
\text { entered the } \\
\text { blackspot } \\
\text { region. }\end{array}$ \\
\hline $\begin{array}{l}\text { Mombasa } \\
\text { Road } \\
\text { Between } \\
\text { Bellevue } \\
\text { to } \\
\text { Cabanas } \\
\text { Blackspot }\end{array}$ & $\begin{array}{l}\text { Exits the } \\
\text { Blackspot (Is } \\
\text { not within } \\
150 \mathrm{~m} \text { of the } \\
\text { Blackspot) }\end{array}$ & $\begin{array}{l}\text { The system } \\
\text { should notify } \\
\text { the user that } \\
\text { they have } \\
\text { exited the } \\
\text { region of the } \\
\text { blackspot. }\end{array}$ & $\begin{array}{l}\text { The user is } \\
\text { notified that } \\
\text { they have } \\
\text { exited the } \\
\text { blackspot } \\
\text { region and } \\
\text { that they are } \\
\text { safe. }\end{array}$ \\
\hline
\end{tabular}

\section{DISCUSSION}

The aim of this study was to build a GPS-based IoT Blackspot Notification System. The solution consisted broadly of a Microcontroller, GPS, and GSM and it was integrated with a mobile device for testing purposes. Several testing activities were carried along different road sections in major highways.

This was done so that to demonstrate the study has fulfilled its objectives. The experiments showed that blackspots coordinates should be known beforehand so. The GPS provides a means of reading blackspots coordinates on the actual road section. An algorithm in the microcontroller tells which coordinates matched the coordinates defining a blackspot region.

Testing used five regions/zones known to be blackspots. The region coordinates were taken and then fed to the algorithm. The program was then uploaded to the microcontroller, which is integrated with the GPS and GSM components. On receiving a signal from the microcontroller, the GSM module conveyed appropriate message to the mobile device.

\section{CONCLUSION}

This study was focused on developing an IoT blackspot identification GPS for drivers. The system uses GPS to find coordinates while a driving on the road. To ensure that project successfully achieves its objectives several components were put together during its development. Through literature review, the suitability of each of the components used in this study was ascertained. It was also important to factor in user expectation; sampled out of drivers were interview regarding their view expectations and suggestions so that the built system fits well in their scenario.

The results obtained from system testing were analysed to validate the usability and credibility of the system. The results showed that the system can be used in real-time environment to assists drivers make right decision whenever they approach a dangerous road section.

The proposed system leans to just providing drivers about the blackspot information and directives. This system can be extended to cover entire traffic events such notifying the drivers about the roadblocks on the roads, alerting drivers whenever there is an accident a head and perhaps whether this accident can result to traffic jams so that he/she can change course.

\section{REFERENCES}

Jørgensen, K., 2009: Concepts of Accident Analysis. Encyclopedia of Occupational Health and Safety. International Labor Organization, Geneva.

Manyara C.G., 2016: Combating Road Traffic Accidents in Kenya: A Challenge for an Emerging Economy. Palgrave Macmillan, New York.

Ekpenyong, E. and Pius, O., 2015: Analysis of Reported Cases of Road Traffic Accidents in Umuahia Metropolis. Journal of Applied Quantitative Methods, 10, 27-35.

World Health Organization, 2009: Global Status Report on Road Safety Time for Action. Geneva, W.H.O.

Olemo, C. D., 2016: Exploring the major causes of road traffic accidents in Nairobi County. University of Nairobi.

Malik, F., A., 2016: Road Accidents and Prevention. International Journal of Engineering Development and Research,5, 40-46.

Chen, H., 2012: Black Spot Determination of Traffic Accident Locations and its Spatial Association Characteristic Analysis Based on GIS. Journal of Geographic Information System, 4, 608-617.

Lewis, K., R. 2018. Road signs that are too small or too confusing. The Washington Post. Retrieved from https://www.washingtonpost.com/realestate/2018/01/25/b2c785 9e-0081-11e8-8acfad2991367d9d_story.html?noredirect=on\&utm_term=.5f4af639 6851 .

Min, W., and Wynter, L. 2011. Real-time road traffic prediction with spatio-temporal correlations. Transportation Research Part C: Emerging Technologies, 19(4), 606-616. 
Anbaroglu, B., Heydecker, B., and Cheng, T. 2016: How Travel Demand Affects Detection of Non-Recurrent Traffic Congestion on Urban Road Networks, Int. Arch. Photogramm. Remote Sens. Spatial Inf. Sci., XLI-B2, 159-164, https://doi.org/10.5194/isprs-archives-XLI-B2-159-2016

Chung, Younshik. 2017. Identification of Critical Factors for Non-Recurrent Congestion Induced by Urban Freeway Crashes and Its Mitigating Strategies. Sustainability, 9 (12): 2331. https://doi.org/10.3390/su9122331

Dumbaugh E, Saha D. and Merlin L. 2020. Toward Safe Systems: Traffic Safety, Cognition, and the Built Environment. Journal of Planning Education and Research. doi:10.1177/0739456X20931915

Tan, R. T., Pettersson, N., and Petersson, L. 2007. Visibility enhancement for roads with foggy or hazy scenes. In IEEE Intelligent Vehicles Symposium, 19-24. IEEE.

Khalilikha, M. and Heaslip, K. 2016. The effects of damage on sign visibility: Journal of Traffic and Transportation Engineering (English Edition), 6(3), 571-581.

Mutune, P. K., Mang'uriu, G. N. and Diang'a, S., 2017: Factors that influence the incidences of road accidents in Kenya: A survey of black spots along Mombasa-Malaba road. International Academic Journal of Information Sciences and Project Management, 2(1), 38-65.

Kenya Police Service (n.d) Accident Black Spots in Kenya https://www.kenyapolice.go.ke/accident-black-spots.html 